\title{
Thank you, Professor Thomas Bajanowski!
}

\author{
Heidi Pfeiffer ${ }^{1}$ - Andreas Schmeling \\ Published online: 26 November 2020 \\ (C) Springer-Verlag GmbH Germany, part of Springer Nature 2020 \\ Dear Colleagues,
}

Prof. Thomas Bajanowski was Editor-in-Chief of the International Journal of Legal Medicine from 2008 to 2020.

During this time he has edited more than 2500 manuscripts for this journal. Furthermore, he was the journal's representative in the International Academy of Legal Medicine.

We would like to take this opportunity to thank him for his excellent work, his untiring efforts for the International Journal of Legal Medicine, and the always trusting collaboration.

In the current team, together with the new Associate Editor Prof. Tony Fracasso, we are committed to continue our work for the International Journal of Legal Medicine at a high level. Additionally, Prof. Tony Fracasso will replace Prof. Thomas Bajanowski as the journal's representative in the International Academy of Legal Medicine.

We look forward to further fruitful cooperation with all editors, reviewers and authors as well as with the Springer representatives responsible for the journal from publisher site, Dr. Pillmann and Mrs. Ullmann.

Heidi Pfeiffer and Andreas Schmeling

\section{Thank you, Professor Thomas Bajanowski!}

On behalf of Springer Nature we would like to extend our gratitude and best wishes to Professor Bajanowski. It has been an extremely productive period for our journal, so we would like to take the opportunity to highlight some of the remarkable developments the International Journal of Legal Medicine has seen during Professor Bajanowski's editorship since 2008.

The number of submissions to the journal more than doubled in the last 12 years. Today the International Journal of Legal Medicine receives over 700 submissions per year. At the same time the number of publications almost tripled since 2008, when the journal published 84 citable items (according to JCR 2009). Last year the journal published a record number of 224 articles.

Heidi Pfeiffer

Heidi.Pfeiffer@ukmuenster.de

1 Institute of Legal Medicine, University Hospital Münster, 48149 Münster, Germany
Remarkably, the citation and full text download rates kept track of the continued growth of the journal proving the popularity and impact of our journal. The International Journal of Legal Medicine has been listed in Q1 of JCR's "Medicine, Legal" category for over 15 years.

Although the workload for the Editorial Team has increased year on year, the editorial processes have stayed robust and fast: It takes about 5 to 6 weeks from submission to first decision. An accepted paper is usually published online in less than 2 weeks' time and is indexed in PubMed within $48 \mathrm{~h}$ of online publication.

The International Journal of Legal Medicine is quite broad in scope with a focus on DNA analysis. Of the 2229 articles published during Professor Bajanowski's editorship since 2008 a number of highly cited articles stand out. It is quite fitting that the most highly cited paper during this period was published in 2008 by Andreas Schmeling, who will now succeed Thomas Bajanowski as the new Co-Editor-in-Chief. The paper has received 310 citations to date: Schmeling, A., Grundmann, C., Fuhrmann, A. et al. Criteria for age estimation in living individuals. Int J Legal Med 122, 457 (2008). https://doi.org/10.1007/s00414-008-0254-2.

So, let us end this brief overview with a very warm "Thank you!" to Professor Bajanowski for 12 years of extremely fruitful, pleasant and enjoyable cooperation. Together with Co-Editor-inChief Professor Heidi Pfeiffer and Associate Editor Professor Andreas Schmeling, he has guided the journal through changing times and has developed the journal to be one of the most respected journals in the field. We are tremendously grateful for all Professor Bajanowski has done for the journal and we wish him very well for his retirement.

We would also like to take the opportunity to warmly welcome Professor Andreas Schmeling as the new Editorin-Chief and Professor Tony Fracasso as the new Associate Editor as of January 2021. We look forward to many more years of fruitful cooperation!

Andrea Pillmann

Isabel Ullmann

Heidelberg, November 2020

Publisher's note Springer Nature remains neutral with regard to jurisdictional claims in published maps and institutional affiliations. 